Original Article (short paper)

\title{
Effect of salbutamol on the cardiovascular response in healthy subjects at rest, during physical exercise, and in recovery phase: a randomized, double-blind, crossover study
}

\author{
Maiane da Silva Feitoza \\ Jaqueline Ribas de Melo \\ Universidade Ibirapuera, UNIB, São Paulo, SP, Brazil \\ Wladimir Musetti Medeiros \\ Universidade Ibirapuera, UNIB, São Paulo, SP, Brazil \\ Universidade Federal de São Paulo, UNIFESP, São Paulo, SP, Brazil \\ Gabriel Grizzo Cucato \\ Universidade Ibirapuera, UNIB, São Paulo, SP, Brazil \\ Hospital Israelita Albert Einstein, São Paulo, SP, Brazil \\ Rafael Stelmach \\ Alberto Cukier \\ Celso Ricardo Fernandes de Carvalho \\ Universidade de São Paulo, USP, SãoPaulo, SP, Brazil \\ Felipe Augusto Rodrigues Mendes \\ Universidade Ibirapuera, UNIB, São Paulo, SP, Brazil \\ Universidade de São Paulo, USP, SãoPaulo, SP, Brazil
}

\begin{abstract}
Aim: To evaluate the effect of the short-acting beta agonists (SABAs) salbutamol on cardiovascular response rest, exercise and recovery phase. Methods: This study was conducted as a randomized, double-blind, placebo controlled, crossover study in 15 healthy adults, with a mean age of $30.2 \pm 6.6$ years. Participants underwent a maximal effort test on two non-consecutive days with $400 \mathrm{mcg}$ of salbutamol or placebo. Throughout the protocol, the variables HR, blood pressure (BP), perceived rate of effort (modified Borg scale) and peak expiratory flow (PEF) were monitored. Results: After salbutamol, baseline HR and PEF had increase from $71 \pm 8$ to $80 \pm 11 \mathrm{bpm}(\mathrm{p}<0.05)$ and $454.0 \pm 64.5$ to 475.3 $\pm 71.4 \mathrm{~L} / \mathrm{min}(\mathrm{p}<0.05)$, respectively. The variables HR, BP and Borg were similar between interventions during all the protocol phases ( $p>0.05)$. Conclusion: Administration of salbutamol increased rest heart rate; however, did not change heart rate, blood pressure and perceived exertion during exercise or recovery. This suggests that the salbutamol administration is safe and does not affect exercise intensity prescription in healthy subjects.
\end{abstract}

Keywords: salbutamol; exercise; eeart rate; blood pressure; healthy subject

\section{Introduction}

Physical exercise has been recommended by various health associations worldwide for prevention and treatment of noncommunicable chronic diseases (NCCDs) for its physical, psychological and social benefit ${ }^{1,2}$. Although physical exercise is highly recommended some individuals can develop exerciseinduced bronchoconstriction (EIB) ${ }^{3,4,5,6}$, which either impair or impedes physical activities. Exercise-induced bronchoconstriction is characterized by transient narrowing of the airways during or after physical exertion and can occur either in the presence or absence of other characteristic features of asthma ${ }^{7,8}$. The prevalence of EIB varies between 5 and $20 \%$ in the general population and 40 an $90 \%$ in known asthmatics 9 .

Several classes of medications have been used in the treatment of EIB, but the most commonly recommended are the short-acting inhaled $\beta$-adrenergic (SABA) agonists, such as salbutamol ${ }^{10,11,12}$. Short-acting $\beta$-adrenergic agonists are generally well tolerated, but commonly increasing blood pressure (BP), heart rate (HR) and can have side effects as tachycardia, palpitations, and anxiety ${ }^{13}$. The incidence and severity of its side effects depend on the dosage, route of administration and the presence of comorbidities such as hypertension, cardiac tachyarrhythmias and coronary insufficiency ${ }^{14}$. The cardiovascular effects of SABAs at resting condition are well known; however, remains unclear its effects on the cardiovascular system during exercise and recovery phase ${ }^{15}$ or how it may alter the physical performance of healthy subjects ${ }^{16}$. Knowing the cardiovascular effects of SABAs during exercise may assist health professionals to prescribe appropriate exercises and minimize the risk of adverse events. Traditionally, the Karvonen formula has been used for the prescription of constant intensity physical exercise ${ }^{17}$. This 
equation is essentially based on chronotropic behaviour during a maximal incremental exercise test. Consequently, autonomic changes due to diseases or medications may negatively influence the accuracy of exercise prescription ${ }^{18}$.

Thus, the aim of this study was to investigate the hypothesis that salbutamol increases cardiovascular responses (heart rate and blood pressure), during exercise and recovery in sedentary healthy subjects. In addition, the salbutamol effects on dyspnoea, peak expiratory flow (PEF), and physical performance (total time and work) were evaluated.

\section{Materials and Methods}

\section{Subjects}

Fifteen healthy subjects aged between 20 and 60 years were included in the study. Participants were excluded with: cardiovascular, psychiatric, other chronic lung diseases, or musculoskeletal diseases that would impair exercise test; current use of medications that may affect the cardiovascular or respiratory response; pregnancy; current participation in an exercise programme; current smokers or ex-smokers; and subjects who answered 'yes' to any of the questions on Physical Activity Readiness Questionnaire (PAR-Q) ${ }^{19}$. The Ethics Review Board of the University approved the study (protocol 1.574.833) and all patients signed an informed consent form.

\section{Experimental design}

This was a randomized, double-blind, placebo-controlled crossover study. Patients were selected to undergo two experimental sessions on 2 non-consecutive days. These sessions included administration of 4 "puffs" of $100 \mu \mathrm{g}$ of salbutamol (Aerolin ${ }^{\circledR}$ spray, GlaxoSmithKline ${ }^{\circledR}$, Brazil) or 4 "puffs" of pressurized inhaler as a placebo (Allen \& Hanburys, Victoria, Australia) from identical devices. The subjects inhaled the drug with spacer device after full expiration and then hold their breath for $10 \mathrm{~s}$. All tests were performed in the evening to avoid circadian effects.

Randomization was performed using the site http://www. randomization.com. The researcher leader prepared and supplied trial drug as two indistinguishable metered-dose inhalers labeled "white" (placebo) and "blue" (salbutamol), which were then administered according to the blinded randomization sequence. The unblinding code was held independently by a researcher uninvolved in the trial conduct, and all measurements, data collection, and data entry were completed before treatment codes were broken.

\section{Protocol}

The subjects were advised to refrain from food, tea, coffee or any other beverages eight hours prior to the test and to abstain from strenuous exercise for 24 hours before the protocol. Each experimental trial comprised the initial $10 \mathrm{~min}$ rest at seated position, salbutamol or placebo inhalation, a second rest of 15 min, exercise test, 2 min of active recovery, 3 minutes of passive standing recovery and 15 minutes of passive sitting recovery. The subjects' heart rate was recorded during the entire experiment by a Polar RS800CX (Polar Electro Oy ${ }^{\circledR}$, Kempele, Finland). The HR average in the last $5 \mathrm{~s}$ of each stage was used for analysis. Auscultatory BP (Becton Dickinson ${ }^{\circledR}$, São Paulo, Brazil) was measured at the end of $10 \mathrm{~min}$ (first rest), at the end of $15 \mathrm{~min}$ after intervention (second rest), every three minutes throughout exercise, and at every $5 \mathrm{~min}$ throughout recovery phase. Perceived rate of effort was measured every 3 min during exercise test and at every $5 \mathrm{~min}$ in recovery stage with modified Borg scale from 0 to $10^{20}$. PEF (72000MM, Medicate ${ }^{\circledR}$, São Paulo, Brazil) was measured at the end of $10 \mathrm{~min}$ (first rest), at the end of $15 \mathrm{~min}$ (second rest) and at each $5 \mathrm{~min}$ in recovery stage. The sequence was repeated on a second day with the other intervention. The values obtained were compared with those predicted for the Brazilian population ${ }^{21}$.

\section{Maximal incremental exercise test}

The tests were performed at the Clinical Hospital at the Medical School of São Paulo University (HC-FMUSP) according to the guidelines of the Brazilian Society of Cardiology ${ }^{22}$. The ergometer used was the Technogym Excite Run 700 Treadmill (Technogym $^{\circledR}$, Cesena, Italy), in accordance with the adapted protocol of effort (attachment 1). The expected $\mathrm{HR}_{\max }(\mathrm{bpm})$ for each individual was calculated with the formula $[1]^{23}$.

$$
\text { HRmax }=208-(0.7 * \text { age })
$$

and the maximum power (watts) during exercise was calculated with the formula $[2]^{24}$.

Powermax $=\operatorname{mass}(\mathrm{Kg}) * 9.81 *$ sine of the angle of inclination* $\operatorname{speed}(\mathrm{m} / \mathrm{s})$

Participants were encouraged to continue the test until they felt limiting symptoms, such as muscle or respiratory fatigue, even if they reached their HRmax. Exhaustion was the criterion for interruption of exercise. When patients expended maximum effort, the protocol parameters were adjusted. Then, the recovery phase commenced.

\section{Target heart rate zone}

The target heart rate $\left(\mathrm{HR}_{\text {Target }}\right)$ zone was calculated by the Karvonen formula [3], using the limits of $60 \%$ and $80 \%$ intensity ${ }^{17}$.

$$
\text { HRTarget }=(\text { HRmax }- \text { HRrest }) *(0.6 \text { or } 0.8)+\text { HRrest }
$$

\section{Statistical analysis}

Considering an average HR difference of $14 \mathrm{bpm}$ with standard deviation of $11 \mathrm{bpm}^{25}$ and a loss of $10 \%$ of subjects during 
follow-up, the sample size calculated to be 13 patients. The normality of data was assessed using the Kolmogorov-Smirnov test. Normally distributed data were expressed as mean and standard deviation (SD). To compare HR between interventions, linear regression was performed to determine the intercept and slope values for each subject. The average intercept and slope values for all participants were calculated and used to generate the regression equations relating to the experimental placebo and salbutamol sessions as described previously ${ }^{26}$. The stages of the incremental test were chosen as the independent variable and HR as the dependent variable. A paired t-test was used to determine whether the intercept, slope, $\mathrm{HR}_{\text {Target }} 60 \%$ and $\mathrm{HR}_{\text {Target }}$ $80 \%$ by Karvonen formula differed between salbutamol and placebo experimental sessions. Comparisons of the systolic blood pressure (SBP), diastolic blood pressure (DBP), Borg, PEF across experimental sessions were performed using Twoway analyses of variance (ANOVA), followed by Scheffe's post hoc tests considering sessions (Salbutamol and Placebo) and stages as main factors.

The significance level was adjusted to $5 \%(\mathrm{p}<0.05)$ for all tests, and SigmaStat 3.5 software (Systat Software, Inc., San Jose, CA, USA) was used for statistical analyses.

\section{Heart rate}

Salbutamol intervention provided an average increase in resting HR of $7 \pm 8 \mathrm{bpm}$, (salbutamol, $80 \pm 11 \mathrm{bpm}$; placebo, $71 \pm 8$ bpm; $\mathrm{p}<0.05)$. All participants took the maximal effort test on 2 days ( $\% \mathrm{HR}_{\max }$ predict: salbutamol, $97.0 \pm 5.8$; placebo, $96.3 \pm 4.6 ; \mathrm{p}>0.05)$ and there were no complications. Also, there were no differences in maximum HR (salbutamol, $180 \pm$ $12 \mathrm{bpm}$; placebo, $179 \pm 10 \mathrm{bpm}$; $\mathrm{p}>0.05$ ) or maximum power (salbutamol, 199.7 \pm 48.2 Watts; placebo, 197.3 \pm 46.2 Watts; $p>0.05$ ) between the groups. This indicates the workload was equal in both experimental sessions. No significant difference was observed between HR interventions during the maximum incremental exercise test. The intercepts of the relationship FC/

\section{Results}

All subjects completed the test protocol without any adverse effects such as palpitation, tremor, headache and rhythm disturbance were observed. The anthropometric characteristics of participants are described in Table 1.

Table 1: Anthropometric characterization of participants

\begin{tabular}{cc}
\hline Variables & $\mathbf{n}=\mathbf{1 5}$ \\
\hline Gender $(\mathrm{F} / \mathrm{M})$ & $(10 / 5)$ \\
Age $(\mathrm{yr})$ & $30.2 \pm 6.6$ \\
Mass $(\mathrm{kg})$ & $65.6 \pm 10.4$ \\
Height $(\mathrm{m})$ & $1.64 \pm 0.4$ \\
BMI $\left(\mathrm{kg} / \mathrm{m}^{2}\right)$ & $24.9 \pm 6.8$ \\
PEF L/m & $458.6 \pm 73.5$ \\
PEF pred & $99.0 \pm 15.2$ \\
\hline
\end{tabular}

All data except gender are given as mean \pm standard deviation (SD). Abbreviations: $\mathrm{BMI}=$ body mass index, $\mathrm{F}=$ female, $\mathrm{kg}=$ kilograms, $\mathrm{kg} / \mathrm{m}^{2}=$ kilograms per square meter, $\mathrm{M}=$ male, $\mathrm{n}=$ number of participants, $\mathrm{PEF}=$ Peak Expiratory Flow

stage were similar between salbutamol and placebo intervention (74.2 \pm 11.7 vs. $72.7 \pm 8.3$, respectively), as were both the salbutamol and placebo slopes $(6.86 \pm 0.6 \mathrm{vs} .6 .82 \pm 0.9$, respectively) (Figure 1). During post-exercise recovery, HR was equivalent between the salbutamol and placebo interventions (Figure 2). Both interventions had a reduction of more than $12 \mathrm{bpm}$ in the first minute of recovery (salbutamol, 31 \pm 9 bpm; placebo, $26 \pm 9$ bpm; $p>0.05$ ). This suggests the kinetic behaviour of HR was similar between interventions during all stages of exercise. $\mathrm{HR}_{\text {Target }} 60 \%$ and $\mathrm{HR}_{\text {Target }} 80 \%$ were similar between salbutamol and placebo intervention $\left(\mathrm{HR}_{\text {Target }} 60 \%=140.1 \pm 10.3\right.$ vs. $\left.137.2 \pm 6.8 \mathrm{bpm} ; \mathrm{p}>0.05\right)$ and $\left(\mathrm{HR}_{\text {Target }} 80 \%=160.5 \pm 11.0\right.$ vs. $158.3 \pm 7.7 \mathrm{bpm} ; \mathrm{p}>$ 0.05 ), respectively (Figure 3 ).

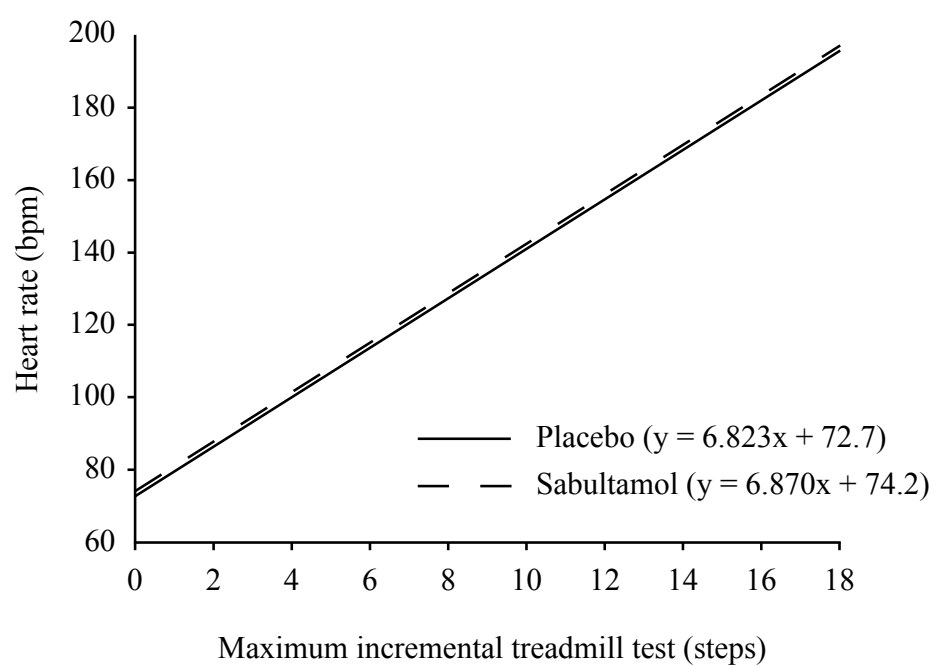

Figure 1. The mean value of the slope and the intercept obtained from the linear regressions of all individuals. Note the absence of differences between linear regressions $(\mathrm{p}>0.05)$. Abbreviations: $\mathrm{bpm}=$ beats per minutes 


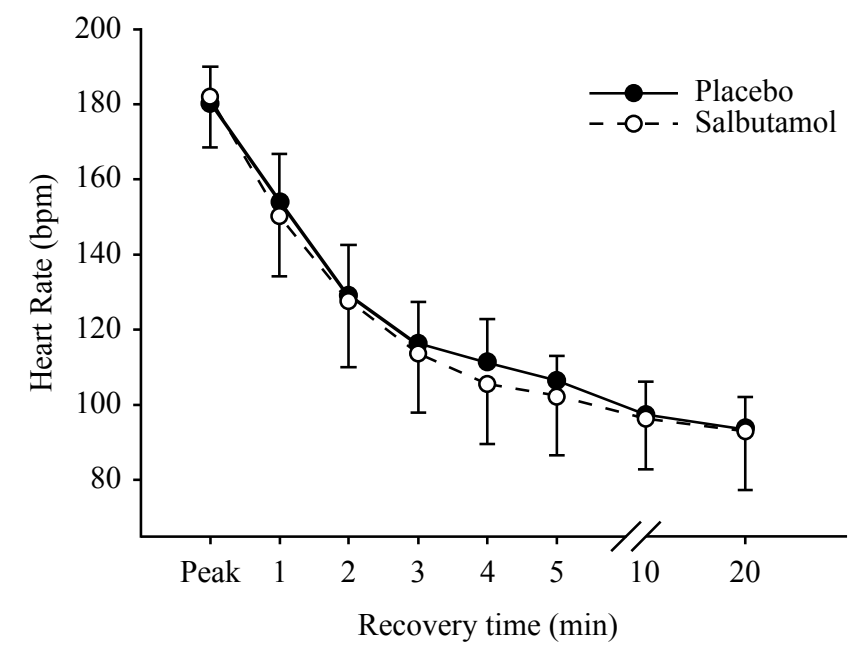

Figure 2. Heart rate recovery in the active ( $2 \mathrm{~min}$ ) and passive ( $2 \mathrm{~min}$ to $20 \mathrm{~min}$ ) phases. Abbreviations: $\min =$ minutes; $\mathrm{bpm}=$ beats per minutes.

\section{Blood pressure, dyspnoea and peak expiratory flow}

SBP, DBP, and perceived exertion were similar in the rest phase, during exercise, and in the recovery phase between experimental

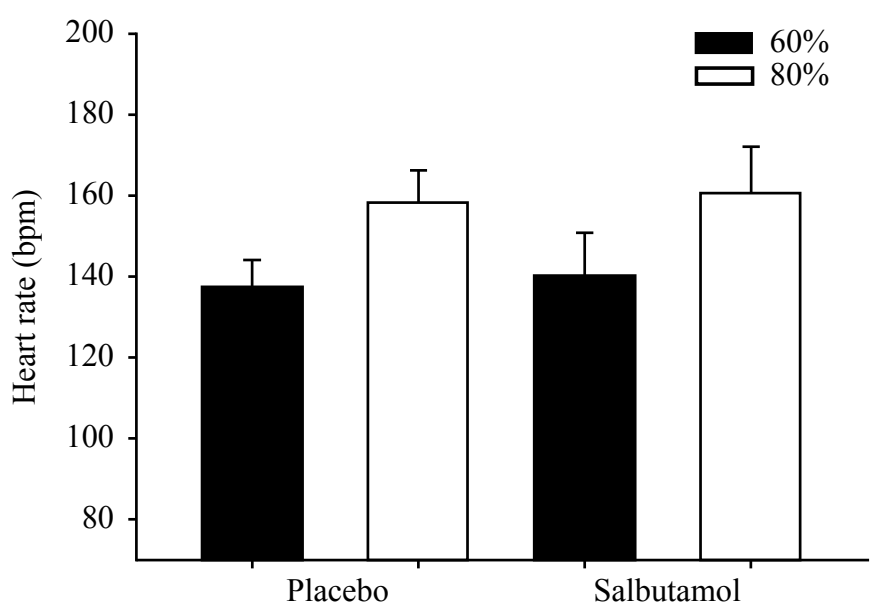

Figure 3. Mean and SD of $\mathrm{HR}_{\text {Target }} 60 \%$ and $\mathrm{HR}_{\text {Target }} 80 \%$ by Karvonen formula.

sessions (Tables 2 and 3, $\mathrm{p}>0.05$ ). Peak Expiratory Flow significantly increased in the salbutamol protocol, from $454.0 \pm$ $64.5 \mathrm{~L} / \mathrm{min}$ to $475.3 \pm 71.4 \mathrm{~L} / \mathrm{min}$ and remained elevated during all the protocol phases (Table $2, \mathrm{p}<0.05$ ).

Table 2: Resting data at $10 \mathrm{~min}$ before (baseline) and $15 \mathrm{~min}$ after placebo and salbutamol interventions, and passive recovery phase at 5, 10, 15, and 20 min after the maximal stress test.

\begin{tabular}{|c|c|c|c|c|c|c|}
\hline \multirow{2}{*}{ Outcomes } & \multicolumn{2}{|r|}{ Rest } & \multicolumn{4}{|c|}{ Passive recovery } \\
\hline & Baseline & 15 min after intervention & $5 \mathrm{~min}$ & $10 \mathrm{~min}$ & $15 \mathrm{~min}$ & $20 \mathrm{~min}$ \\
\hline HR (bpm) placebo & $78 \pm 15$ & $71 \pm 8$ & $105 \pm 6$ & $97 \pm 9$ & $93 \pm 8$ & $91 \pm 8$ \\
\hline HR (bpm) salbutamol & $78 \pm 14$ & $80 \pm 12 *$ & $104 \pm 13$ & $96 \pm 13$ & $93 \pm 15$ & $90 \pm 14$ \\
\hline $\mathrm{SBP}(\mathrm{mmHg})$ placebo & $103.8 \pm 10.4$ & $107.7 \pm 9.3$ & $113.3 \pm 14.3$ & $110.0 \pm 13.4$ & $110.7 \pm 11.9$ & $100 \pm 12.5$ \\
\hline SBP (mmHg) salbutamol & $106 \pm 12.1$ & $101.5 \pm 14.6$ & $108.4 \pm 11.7$ & $108.4 \pm 10.9$ & $103.8 \pm 18.2$ & $104 \pm 17.0$ \\
\hline DBP $(\mathrm{mmHg})$ placebo & $70.0 \pm 12.9$ & $67.7 \pm 10.9$ & $69.2 \pm 9.9$ & $69.2 \pm 9.9$ & $70.0 \pm 9.1$ & $68.6 \pm 9.1$ \\
\hline DBP (mmHg) salbutamol & $70.8 \pm 9.2$ & $70.0 \pm 9.6$ & $73.1 \pm 10.7$ & $71.5 \pm 7.7$ & $70.8 \pm 8.3$ & $70.6 \pm 8.5$ \\
\hline PEF (L/min) placebo & $440.6 \pm 81.4$ & $458.6 \pm 77.6$ & $463.3 \pm 71.9$ & $464.0 \pm 66.9$ & $467.3 \pm 76.4$ & $468.4 \pm 82.1$ \\
\hline PEF (L/min) salbutamol & $454.0 \pm 64.5$ & $475.3 \pm 71.4^{* \dagger}$ & $470.7 \pm 65.8^{\dagger}$ & $472.0 \pm 61.8^{\dagger}$ & $481.3 \pm 67.8^{\dagger}$ & $480.8 \pm 72.8^{* \dagger}$ \\
\hline Borg placebo & $0 \pm 0$ & $0 \pm 0$ & $2.7 \pm 1.8$ & $1.2 \pm 0.7$ & $0.6 \pm 0.5$ & $0.2 \pm 0.4$ \\
\hline Borg salbutamol & $0 \pm 0$ & $0 \pm 0$ & $2.8 \pm 1.3$ & $1.6 \pm 1.1$ & $1.0 \pm 0.8$ & $0.4 \pm 0.5$ \\
\hline
\end{tabular}

All data are given as mean \pm standard deviation $(\mathrm{SD})$. Abbreviations: $\mathrm{HR}=$ heart rate, $\mathrm{SBP}=$ systolic blood pressure, $\mathrm{DBP}=$ diastolic blood pressure, $\mathrm{PEF}=$ peak expiratory flow, Borg = Borg Rating of Perceived Exertion. Symbols: *placebo vs. salbutamol; $\mathrm{p}<0.05$. $\dagger$ Compared with pre-salbutamol; $\mathrm{p}<0.05$.

Table 3: Blood pressure response and perceived rate of effort (modified Borg scale) during maximal incremental exercise test.

\begin{tabular}{ccccccc}
\hline \multicolumn{6}{c}{ Maximal incremental exercise test } \\
\hline Outcomes & $\mathbf{3}$ min & $\mathbf{6}$ min & $\mathbf{9}$ min & 12 min & Peak \\
\hline SBP $(\mathrm{mmHg})$ placebo & $110.6 \pm 11.6$ & $112.0 \pm 10.1$ & $118.6 \pm 12.5$ & $131.5 \pm 19.5$ & $132.0 \pm 26.5$
\end{tabular}




\begin{tabular}{cccccc} 
SBP (mmHg) salbutamol & $108.0 \pm 11.7$ & $110.6 \pm 13.8$ & $119.3 \pm 15.6$ & $125.7 \pm 21.6$ & $130.0 \pm 23.9$ \\
DBP (mmHg) placebo & $67.3 \pm 9.6$ & $69.3 \pm 8.8$ & $68.0 \pm 9.4$ & $71.5 \pm 12.1$ & $71.3 \pm 13.5$ \\
DBP (mmHg) salbutamol & $70.7 \pm 9.2$ & $73.3 \pm 8.6$ & $71.3 \pm 10.8$ & $74.2 \pm 11.6$ & $72.8 \pm 12.0$ \\
Borg placebo & $0.7 \pm 0.8$ & $1.6 \pm 0$ & $2.9 \pm 1.6$ & $5.5 \pm 2.4$ & $7.6 \pm 1.7$ \\
Borg salbutamol & $0 \pm 0$ & $0 \pm 0$ & $2.9 \pm 1.3$ & $5.2 \pm 2.4$ & $8.1 \pm 1.1$ \\
\hline
\end{tabular}

All data are given as mean \pm standard deviation (SD). Abbreviations: $\mathrm{SBP}=$ systolic blood pressure, $\mathrm{DBP}=$ diastolic blood pressure, Borg $=$ Borg Rating of Perceived Exertion.

\section{Discussion}

The study aimed to evaluate the effect of salbutamol on the cardiovascular system in healthy subjects at rest, during exercise, and during recovery. The main results of the study were: 1) a significant increase in HR in the experimental salbutamol session only in relation to the rest period; 2) similar cardiovascular responses and perceived exertion between salbutamol and placebo during the exercise and recovery phases.

In this study, it was observed that the use of salbutamol significantly increased resting HR by an average of $9 \pm 11 \mathrm{bpm}$. These results were similar to those found by Cekici, Valipour, Kohansal, Burghuber ${ }^{25}$, where observed an average increase in HR of $13 \mathrm{bpm}$ in healthy subjects after administration of 200 $\mu \mathrm{g}$ of salbutamol ${ }^{25}$. Edgell, Moore, Chung, Byers, Stickland ${ }^{15}$ reported an average increase in resting HR of $8 \mathrm{bpm}$ after administration of $400 \mu \mathrm{g}$ of salbutamol ${ }^{15}$. Salbutamol is a $\beta_{2}$ agonist that also activates the $\beta$-adrenergic receptors in the cardiovascular system. Consequently, it promotes positive chronotropism and inotropism by a reduction of the parasympathetic nervous system and an increase of the sympathetic nervous system ${ }^{27}$ that can explain these results.

The cardiovascular effects of SABAs at resting condition are widely known; however, SABAs effects on HR and BP during exercise and recovery remains poorly understood. We are aware of only one study that evaluated the influences of albuterol (similar salbutamol) on cardiovascular response in healthy subjects during exercise, and observed that salbutamol have no influences in $\mathrm{HR}$ and $\mathrm{BP}^{28}$. Although our results show similar effects of salbutamol on HR and BP during exercise, in the present study salbutamol were delivered via metered-dose inhaler (MDI) in sample of men and women, while Freeman el al., albuterol was delivered via nebulizer only in men $^{28}$. The pressurized MDI is small, portable, can be used very quickly, have high lung deposition fraction and is less expensive than nebulizer ${ }^{29}$. Because of these features, it is the preferred device. Our finds showed that the use of the Salbutamol does not compromise the relationship between the chronotropic response and the load, even with changes in resting heart rate values. In this way, the prescription of the physical exercise based on the Karvonen formula seems to us adequate and safe.

In addition we analysed, for the first time, the influences of salbutamol on heart rate recovery and observed that the decrease in HR during the recovery phase in the first minute was greater than $12 \mathrm{bpm}$ for all participants and did not differ between placebo and salbutamol intervention. This indicates that the use of salbutamol does not adversely affect HR recovery, which is closely linked to risk of cardiovascular disease and to mortality in various diseases ${ }^{30,31,32}$.

Systolic and diastolic blood pressure was similar after placebo and salbutamol administration. This was also found in studies by Edgell, Moore, Chung, Byers, Stickland ${ }^{15}$ Cekici, Valipour, Kohansal, Burghuber ${ }^{25}$, Jartti, Kaila, Tahvanainen, Kuusela, Vanto, Valimaki ${ }^{27}$, Antonelli et al. ${ }^{29}$, and Snyder, Wong, Foxx-Lupo, Wheatley, Cassuto, Patanwala 15,25,27,29,33. Blood pressure and perception of effort during exercise and recovery did not change significantly between interventions that are similar to the results observed by Freeman el $\mathrm{al}^{28}$. As in previous studies, salbutamol induced significant bronchodilation in healthy subjects ${ }^{34,35,36}$. However, this improvement have no ergogenic effect ${ }^{37}$. This is probably due to cardiovascular, but not respiratory, limitations observed in healthy individuals exposed to high-intensity exercise under normoxic conditions ${ }^{38}$.

In practical terms, this study indicates that administration of salbutamol to healthy subjects does not affect HR during exercise and recovery. Thus, HR does not need to be adjusted for exercise intensity after administration of salbutamol. In addition, the responses of blood pressure at rest, during exercise, and during recovery were similar between experimental sessions, indicating that the use of salbutamol is considered safe from the point of view of cardiovascular risk in healthy subjects.

The study has some limitations that must be highlighted. The study analysed the acute effects of salbutamol on the cardiovascular system only. Future studies should assess the chronic effects of this medication. The study included only healthy subjects without a history of EIB. In addition, only an ergometric test was administered and cardiopulmonary exercise test could provide a better characterization of the ventilatory and cardiopulmonary responses during exercise after administration of salbutamol.

\section{Conclusion}

Administration of salbutamol increased rest heart rate; however, did not change heart rate, blood pressure and perceived exertion during exercise or recovery. This suggests that the salbutamol administration is safe and does not affect exercise intensity prescription in healthy subjects. 


\section{References}

1. Pedersen BK, Saltin B. Exercise as medicine - evidence for prescribing exercise as therapy in 26 different chronic diseases. Scand J Med Sci Sports. 2015;25 Suppl 3:1-72.

2. Guimaraes GV, Ciolac EG. Physical activity: practice this idea. American journal of cardiovascular disease. 2014;4(1):31-3.

3. Randolph C. Pediatric exercise-induced bronchoconstriction: contemporary developments in epidemiology, pathogenesis, presentation, diagnosis, and therapy. Current allergy and asthma reports. 2013;13(6):662-71.

4. Boulet LP, Turmel J, Cote A. Asthma and exercise-induced respiratory symptoms in the athlete: new insights. Curr Opin Pulm Med. 2017;23(1):71-7.

5. Khan DA. Exercise-induced bronchoconstriction: burden and prevalence. Allergy Asthma Proc. 2012;33(1):1-6.

6. Price OJ, Hull JH, Backer V, Hostrup M, Ansley L. The impact of exercise-induced bronchoconstriction on athletic performance: a systematic review. Sports Med. 2014;44(12):1749-61.

7. Parsons JP, Hallstrand TS, Mastronarde JG, Kaminsky DA, Rundell KW, Hull JH, et al. An official American Thoracic Society clinical practice guideline: exercise-induced bronchoconstriction. Am J Respir Crit Care Med. 2013.01;187(9):1016-27.

8. Weiler JM, Anderson SD, Randolph C, Bonini S, Craig TJ, Pearlman DS, et al. Pathogenesis, prevalence, diagnosis, and management of exercise-induced bronchoconstriction: a practice parameter. Annals of allergy, asthma \& immunology : official publication of the American College of Allergy, Asthma, \& Immunology. 2010;105(6 Suppl):S1-47.

9. Weiler JM, Bonini S, Coifman R, Craig T, Delgado L, Capao-Filipe $\mathrm{M}$, et al. American Academy of Allergy, Asthma \& Immunology Work Group report: exercise-induced asthma. The Journal of allergy and clinical immunology. 2007 Jun;119(6):1349-58

10. Koch S, Ahn JR, Koehle MS. High-Dose Inhaled Salbutamol Does Not Improve 10-km Cycling Time Trial Performance. Med Sci Sports Exerc. 2015;47(11):2373-9.

11. Koch S, Karacabeyli D, Galts C, MacInnis MJ, Sporer BC, Koehle MS. Effects of inhaled bronchodilators on lung function and cycling performance in female athletes with and without exerciseinduced bronchoconstriction. J Sci Med Sport. 2015;18(5):607-12.

12. Koch S, MacInnis MJ, Sporer BC, Rupert JL, Koehle MS. Inhaled salbutamol does not affect athletic performance in asthmatic and non-asthmatic cyclists. Br J Sports Med. 2015;49(1):51-5.

13. Molis MA, Molis WE. Exercise-induced bronchospasm. Sports health. 2010;2(4):311-7.

14. Rohr AS, Spector SL, Rachelefsky GS, Katz RM, Siegel SC. Efficacy of parenteral albuterol in the treatment of asthma. Comparison of its metabolic side effects with subcutaneous epinephrine. Chest. 1986 Mar;89(3):348-51.

15. Edgell H, Moore LE, Chung C, Byers BW, Stickland MK. Shortterm cardiovascular and autonomic effects of inhaled salbutamol. Respir Physiol Neurobiol. 2016;231:14-20.

16. Pluim BM, de Hon O, Staal JB, Limpens J, Kuipers H, Overbeek SE, et al. beta(2)-Agonists and physical performance: a systematic review and meta-analysis of randomized controlled trials. Sports Med. 2011,01;41(1):39-57.
17. Garber CE, Blissmer B, Deschenes MR, Franklin BA, Lamonte MJ, Lee IM, et al. American College of Sports Medicine position stand. Quantity and quality of exercise for developing and maintaining cardiorespiratory, musculoskeletal, and neuromotor fitness in apparently healthy adults: guidance for prescribing exercise. Med Sci Sports Exerc. 2011 Jul;43(7):1334-59.

18. Medeiros WM, De Luca FA, Figueredo Junior A, Mendes FAR, Gun C. Heart rate recovery improvement in patients following acute myocardial infarction: Exercise training, $\beta$-blocker therapy, or both. Clin Physiol Funct Imaging. 2017 Mar 2. DOI:10.1111/ cpf. 12420 .

19. Thomas S, Reading J, Shephard RJ. Revision of the Physical Activity Readiness Questionnaire (PAR-Q). Canadian journal of sport sciences $=$ Journal canadien des sciences du sport. 1992 Dec;17(4):338-45.

20. Joffe D, Berend N. Assessment and management of dyspnoea. Respirology. 1997 Mar;2(1):33-43

21. Pereira CAC, Barreto SP, Simões JG, Pereira FWL, Gerstler JG, Nakatani J. Valores de referência para espirometria em uma amostra da população brasileira adulta. J Pneumol. 1992;18(1):10-22.

22. Meneghelo RS, Araújo CGS, Stein R, Mastrocolla LE, Albuquerque PF, Serra SM. III Diretrizes da Sociedade Brasileira de Cardiologia sobre Teste Ergométrico. Arq Bras Cardiol. 2010;95(5 supl.1):1-26.

23. Tanaka H, Monahan KD, Seals DR. Age-predicted maximal heart rate revisited. J Am Coll Cardiol. 2001;37(1):153-6.

24. Bush A, Busst CM, Johnson S, Denison DM. Rebreathing method for the simultaneous measurement of oxygen consumption and effective pulmonary blood flow during exercise. Thorax. 1988;43(4):268-75.

25. Cekici L, Valipour A, Kohansal R, Burghuber OC. Short-term effects of inhaled salbutamol on autonomic cardiovascular control in healthy subjects: a placebo-controlled study. British journal of clinical pharmacology. 2009;67(4):394-402.

26. Swain DP, Leutholtz BC. Heart rate reserve is equivalent to $\%$ VO2 reserve, not to \%VO2max. Med Sci Sports Exerc. 1997;29(3):410-4.

27. Jartti T, Kaila T, Tahvanainen K, Kuusela T, Vanto T, Valimaki I. The acute effects of inhaled salbutamol on the beat-to-beat variability of heart rate and blood pressure assessed by spectral analysis. British journal of clinical pharmacology. 1997;43(4):421-8.

28. Freeman W, Packe GE, Cayton RM. Effect of nebulised salbutamol on maximal exercise performance in men with mild asthma. Thorax. 1989 Nov;44(11):942-7.

29. Antonelli A, Torchio R, Bertolaccini L, Terzi A, Rolfo F, Agostoni $\mathrm{P}$, et al. Contribution of beta-adrenergic receptors to exerciseinduced bronchodilatation in healthy humans. Respir Physiol Neurobiol. 2012,15;184(1):55-9.

30. Cole CR, Blackstone EH, Pashkow FJ, Snader CE, Lauer MS. Heart-rate recovery immediately after exercise as a predictor of mortality. N Engl J Med. 1999;341(18):1351-7.

31. Nishime EO, Cole CR, Blackstone EH, Pashkow FJ, Lauer MS. Heart rate recovery and treadmill exercise score as predictors of mortality in patients referred for exercise ECG. JAMA. 2000;284(11):1392-8. 
32. Peres P, Carvalho AC, Perez AB, Medeiros WM. Abnormal heart rate recovery and deficient chronotropic response after submaximal exercise in young Marfan syndrome patients. Cardiology in the young. 2016;26(7):1274-81.

33. Snyder EM, Wong EC, Foxx-Lupo WT, Wheatley CM, Cassuto NA, Patanwala AE. Effects of an inhaled beta2-agonist on cardiovascular function and sympathetic activity in healthy subjects. Pharmacotherapy. 2011;31(8):748-56.

34. Goubault C, Perault MC, Leleu E, Bouquet S, Legros P, Vandel $\mathrm{B}$, et al. Effects of inhaled salbutamol in exercising non-asthmatic athletes. Thorax. $2001 \mathrm{Sep}$;56(9):675-9

35. Norris SR, Petersen SR, Jones RL. The effect of salbutamol on performance in endurance cyclists. Eur J Appl Physiol Occup Physiol. 1996;73(3-4):364-8

36. Heir T, Stemshaug H. Salbutamol and high-intensity treadmill running in nonasthmatic highly conditioned athletes. Scand J Med Sci Sports. 1995 Aug;5(4):231-6.

37. Koch S, MacInnis MJ, Rupert JL, Sporer BC, Koehle MS. Pharmacogenetic Effects of Inhaled Salbutamol on 10-km Time Trial Performance in Competitive Male and Female Cyclists. Clinical journal of sport medicine : official journal of the Canadian Academy of Sport Medicine. 2016;26(2):145-51.

38. Ferretti G. Maximal oxygen consumption in healthy humans: theories and facts. Eur J Appl Physiol. 2014;114(10):2007-36.

\section{Appendix 1.}

\begin{tabular}{|c|c|c|}
\hline Stage (min) & Speed $\left(\mathbf{k m} \cdot \mathrm{h}^{-1}\right)$ & Grade (\%) \\
\hline 1 & 1.7 & 0 \\
\hline 2 & 3.5 & 0 \\
\hline 3 & 4 & 2 \\
\hline 4 & 4 & 4.5 \\
\hline 5 & 4.8 & 0 \\
\hline 6 & 5 & 3 \\
\hline 7 & 5.5 & 4 \\
\hline 8 & 5.5 & 8 \\
\hline 9 & 5.5 & 12 \\
\hline 10 & 5.8 & 14 \\
\hline 11 & 6.2 & 15 \\
\hline 12 & 6.6 & 15 \\
\hline 13 & 6.8 & 15 \\
\hline 14 & 7.2 & 15 \\
\hline 15 & 7.8 & 15 \\
\hline 16 & 8.3 & 15 \\
\hline 17 & 8.8 & 15 \\
\hline 18 & 9.2 & 15 \\
\hline
\end{tabular}

\begin{tabular}{lcc}
\hline 1 & 2.4 & 2.5 \\
2 & 2.4 & 2.5 \\
3 & 0 & 0 \\
4 & 0 & 0 \\
5 & 0 & 0 \\
\hline
\end{tabular}

Figure 1. Incremental protocol test. Abbreviations: $\mathrm{km}=$ kilometre; $\min =$ minutes; $\mathrm{h}=$ hour; $\%=$ percentage.

\section{Acknowledgements}

We would like to thank Cybele Christine Berto Marques da Silva and Aline Grandi dos Santos for their ambulatory assistance during data collection.

\section{Corresponding author}

Felipe Augusto Rodrigues Mendes

Departamento de Fisioterapia da Universidade Ibirapuera

Avenida Interlagos, 1329, CEP 04661-100, Chácara Flora, São Paulo, SP, Brasil

Email: felipemendes@usp.br

Manuscript received on March 19, 2017

Manuscript accepted on July 3, 2017

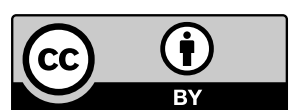

Motriz. The Journal of Physical Education. UNESP. Rio Claro, SP, Brazil - eISSN: 1980-6574 - under a license Creative Commons - Version 3.0 